\title{
PLANEJAMENTO ESTRATÉGICO PARA ABERTURA DE CANAL DE VENDA DE UMA FÁBRICA DE ARTES EM MADEIRA
}

\author{
STRATEGIC ASSESSMENT FOR OPENING A SALES CHANNEL IN A WOODEN \\ ARTS FACTORY
}

\author{
Emanuel Campigotto Sandri \\ Doutorando em Administração \\ Universidade Federal do Paraná - UFPR \\ Curitiba, Paraná - Brasil \\ emanuel.sandri@hotmail.com \\ André Ricardo do Rosário Contani \\ Doutorando em Administração \\ Universidade Federal do Paraná - UFPR \\ Curitiba, Paraná - Brasil \\ acontani@gmail.com \\ Giovani Cruzara \\ Doutorando em Administração \\ Universidade Federal do Paraná - UFPR \\ Curitiba, Paraná - Brasil \\ giovani.cruzara@outlook.com \\ Júlia Mitsue Vieira Cruz Kumasaka \\ Doutoranda em Administração \\ Universidade de São Paulo - USP \\ São Paulo, São Paulo- Brasil \\ juliamitsue@ hotmail.com
}

\begin{abstract}
Resumo: O conceito de planejamento estratégico pode ser definido como um método cujo intuito é diminuir riscos ao prever o futuro a partir de um processo sistemático e contínuo. Nesse sentido, este relato técnico-científico teve como objetivo analisar a abertura de um novo canal de venda diante do planejamento estratégico e do contexto competitivo de uma empresa estabelecida na cidade de Cascavel, no Paraná. O método baseou-se no estudo de caso único qualitativo e de natureza descritiva-explicativa, com entrevistas com o gestor. Acompanhou-se e auxiliou-se na implantação de um novo canal de venda derivado do planejamento estratégico da empresa, cujo desenvolvimento se baseou no uso de ferramentas como a análise de cenário, análise do posicionamento, análise SWOT e análise dos canais. Como resultado, entende-se que a empresa está ciente dos seus pontos fortes e fracos, bem como das oportunidades presentes no mercado que poderão ser aproveitadas e das ameaças que deverão ser tratadas com cautela. Ainda que não esteja formalizado e registrado em um único documento escrito, o processo de planejamento estratégico foi conduzido e está acessível ao gestor para a definição dos cursos de ação da empresa.
\end{abstract}

Palavras-chave: Competitividade. Gestão organizacional. Planejamento estratégico. Gestão de canais de venda.

Abstract: Strategic planning can be conceptualized as a method to reduce risks by predicting the future through a systematic and continuous process. In this sense, this technical-scientific report aimed to analyze the opening of a new sales channel facing the strategic planning and competitive context of a company established in the city of Cascavel, Paraná. The method was based on a qualitative case study with an explanatory-descriptive nature, with interviews with the manager. The implementation of a new sales channel derived from the company's strategic planning was followed and assisted. The development was based on the use of such as scenario analysis, positioning analysis, SWOT analysis and channel analysis. As a result, the company is aware of its strengths and weaknesses, as well as the opportunities present in the market that can be taken advantage of and the threats that should be treated with caution. Even though it is not formalized and registered in a single written document, the strategic planning process was conducted and is accessible to the manager for the definition of the company's courses of action.

Keywords: Competitiveness. Organizational management. Strategic planning. Management of Sales channels.

\section{Cite como}

American Psychological Association (APA)

Sandri, E. C., Contani, A. R. R., Cruzara, G., \& Kumasaka, J. M. V. C. (2021, jan./jun.). Planejamento estratégico para abertura de canal de venda de uma fábrica de artes em madeira. Revista Inovação, Projetos e Tecnologias - IPTEC, São Paulo, 9(1), 109-123.

https://doi.org/10.5585/iptec.v9i1.19085. 


\section{Introdução}

O planejamento estratégico tem o seu desenvolvimento marcado pelas mudanças ocorridas desde a Revolução Industrial, que modificou a economia e os sistemas de produção. Nesse contexto, foram conduzidas diversas pesquisas acadêmicas sobre a gestão das empresas e o uso do planejamento estratégico (Andreuzza, 2008).

Dentre essas pesquisas, há o planejamento sobre a comercialização, a qual diz respeito à concepção e à gestão dos canais por meio dos quais a organização e seus produtos chegam ao mercado. É por meio desta que se materializa a troca entre a empresa e seus consumidores e, portanto, deve ser capaz de gerar e satisfazer a demanda dos produtos para a organização. Formalmente, os canais de comercialização são conjuntos de organizações interdependentes envolvidas no processo de disponibilizar um produto ou serviço para uso ou consumo (Kotler \& Keller, 2006; Pascarella, 2015).

Buscando estender os conhecimentos e aplicações quanto ao planejamento estratégico empregado na comercialização, o objetivo deste trabalho é analisar a abertura de um novo canal de venda diante do planejamento estratégico e do contexto competitivo da empresa em estudo. Como recorte, avalia-se o processo decisório de abertura de um novo canal de venda com o auxílio de ferramentas estratégicas.

A pesquisa foi conduzida em uma empresa do setor fabril, com foco em fabricação de artefatos diversos em madeira, excetuando móveis, que está localizada na cidade de CascavelPR. Uma vez que a referida empresa não tem o planejamento estratégico implementado na execução de suas atividades de gestão, espera-se contribuir a partir da demonstração do potencial de melhoria que o auxílio de ferramentas estratégicas têm na tomada de decisão.

\section{Revisão de literatura}

A estratégia como conceito, conforme Mintzberg (2010), tem origem na concepção militar de enfrentamento em batalhas. O estrategista, chamado de general nesse contexto, deve ser capaz de conduzir a organização para a plena realização dos seus objetivos. Nesse sentido, a estratégia pode ser considerada a partir de duas perspectivas: como resultado de um planejamento (deliberada) ou fruto de ações e reações não antecipadas frente a contingências (emergente). No encontro dessas duas abordagens é aplicado a estratégia organizacional (Mintzberg, 2010).

Assim, cabe à organização se antecipar e conduzir o planejamento estratégico na medida em que a alocação e o desenvolvimento de seus recursos podem ser otimizados. Entende-se o 
planejamento estratégico como um processo vinculado à gestão administrativa que visa à organização, previsão e produção de planos de ação, sobretudo de longo prazo, com o objetivo de auferir maiores ganhos para a empresa. O diferencial no uso do planejamento estratégico reside na definição metodológica que norteia, de modo sustentável, o direcionamento da atuação da empresa no mercado (Oliveira, 2004).

Assim, o conceito de planejamento estratégico pode ser definido como um método com o intuito de diminuir riscos ao prever o futuro a partir de um processo sistemático e contínuo (Drucker, 1997). Quando se trata de formular e definir os rumos da empresa, deve-se levar em conta tanto os aspectos internos quanto os externos à organização (Oliveira, 2004). Ademais, deve-se buscar seguir e executar aquilo que foi planejado, de modo que se obtenha o posicionamento estratégico esperado.

Uma vez que a estratégia tem a sua origem em um conceito militar que envolve o alcance do sucesso em batalhas, o planejamento estratégico pode ser estudado a partir de técnicas militares de planejamento de contingências e de estratégias de ação (de Oliveira, Perez Jr., \& Silva, 2011). Assim, dado o ambiente competitivo de negócios, cuja característica de acirrada competição se assemelha ao contexto de disputa militar, pode-se adaptar essas técnicas no desenvolvimento do planejamento estratégico. Nesse sentido, deve-se buscar, primeiramente, compreender o macroambiente setorial e tecnológico para então empreender a definição das diretrizes estratégicas. A partir do mapeamento do contexto competitivo, identifica-se o propósito da organização, que se traduz na definição da missão, visão e valores organizacionais.

Porter $(1979,1976)$ apresenta a estratégia a partir da noção de vantagem competitiva. Trata-se da aquisição, pela organização, de recursos que promovem um diferencial que outras organizações não podem replicar - não sem algum investimento ou esforço para o desenvolvimento de competências. A empresa que alcança uma vantagem competitiva possui a vantagem de ser a primeira a organizar seus recursos para tal finalidade, conseguindo lançar-se à frente da concorrência.

A lógica para o desenvolvimento do planejamento estratégico está baseada no conhecimento do contexto competitivo. Assim, busca-se, primeiramente, projetar o ambiente competitivo futuro, traçando o cenário macroeconômico que será determinante para a empresa (Hitt, Ireland, \& Hoskisson, 2011). A partir do reconhecimento de como o cenário se projeta, a empresa tem condições de estabelecer suas ações para o cumprimento das metas organizacionais.

Cabe ressaltar que a proposta de Porter se baseia em uma análise de um setor de concorrência e não para uma empresa específica. Nesse sentido, o modelo de cinco forças 
(Porter, 1979) oferece meios de análise do ambiente competitivo e representa o posicionamento da organização em termos de cinco forças atuantes: poder de barganha de clientes, poder de barganha de fornecedores, ameaça de novos entrantes, ameaça de produtos substitutos e rivalidade entre concorrentes.

Como ferramenta para o desenvolvimento do planejamento estratégico, destaca-se a análise SWOT (Mintzberg, 2010), que representa o acrônimo em inglês para a análise organizacional de forças (strengths), fraquezas (weaknesses), oportunidades (opportunities) e ameaças (threats). Pela lógica do planejamento, uma vez determinados o cenário futuro e o contexto competitivo, a análise SWOT representa o conhecimento sobre a interface entre o ambiente externo (oportunidades e ameaças) e interno (forças e fraquezas) à empresa.

Neste aspecto, buscou-se a aplicação da análise SWOT com o objetivo de analisar a abertura de um novo canal de venda diante do planejamento estratégico e do contexto competitivo da empresa em estudo. Os métodos e aplicações técnicas utilizados no presente trabalho são descritos na próxima seção.

\section{Metodologia de tratamento do objeto}

Este estudo foi decorrente de uma consultoria realizada entre os meses de abril e setembro de 2018. Acompanhou-se e auxiliou-se na implantação de um novo canal de venda derivado do planejamento estratégico da empresa, cujo desenvolvimento se baseou no uso de ferramentas de diagnóstico, como análise SWOT, e de análise de cenário. Para isso, adotou-se a metodologia pesquisa ação-técnica, que se constitui como uma abordagem específica ao aplicar um modelo existente em um contexto específico a ser estudado (TRIPP, 2005).

Durante o período citado, ocorreram visitas semanais à organização envolvendo conversas com o proprietário da empresa e análise documental. Ao todo, foram realizados 12 encontros com o proprietário da empresa em estudo, com duração média de duas horas, totalizando vinte e quatro horas de entrevista. Além disso, diversos documentos relevantes para o objetivo da consultoria foram analisados, entre eles: relatórios de vendas, relatório de empresas ativas na Junta Comercial do município de Cascavel e relatório de produção/hora. Assim, foi possível identificar aspectos como a quantidade e localização dos clientes, quantidade de itens produzidos e vendidos, além da capacidade de cada canal de venda.

A pesquisa foi realizada em três ciclos, sendo eles: I) Caracterização e identificação de mercado da empresa, realizada por meio da análise de relatórios internos e do mercado, sendo possível entender a estrutura do setor comercial da organização e como a empresa estava 
inserida no seu setor. II) Análise da capacidade de produção da organização por meio de análises que serão descritas na próxima sessão. III) Identificação das oportunidades de abertura de um novo canal de venda para o aumento do faturamento da empresa.

\section{Resultados alcançados}

\subsection{Caracterização da empresa}

A empresa Alfa, aqui apresentada com um nome fictício, está estabelecida desde 2017 em Cascavel-PR, onde atua na fabricação de artefatos diversos de madeira, como luminárias, quadros decorativos, porta-joias, etc. com base em um processo artesanal e artístico. Entre o seu portfólio, excetuam-se móveis. O único proprietário integralizou o capital social e fez os aportes de capital quando necessário. Segundo o proprietário, a missão da empresa é comercializar produtos e desenvolver serviços que atendam às expectativas e desejos de seus clientes. Para isso, possui uma loja física na cidade de Cascavel, no estado do Paraná. Além do sócio, a empresa conta com três funcionários, sendo dois na produção dos artefatos em madeira e uma pessoa responsável pela área administrativa. Sob o ponto de vista administrativo, utilizase um sistema apenas para emissão de nota fiscal e apuração de impostos, lançando mão do uso de planilhas conforme necessidade específica.

\subsection{Análise de cenário}

O ambiente competitivo da empresa está fortemente influenciado pelos fatores de produção/fornecimento, vendas e distribuição. Como elemento de incerteza no setor, identificou-se que a questão produtiva concentra o maior fator de impacto. Isso é reflexo do grau elevado de dificuldade na obtenção e desenvolvimento de mão-de-obra qualificada, visto que há pouco espaço para mecanização na fabricação dos produtos, dada a natureza das atividades executadas.

O gestor apontou, entre as macrotendências, que o meio ambiente possui potencial significativo de afetar e influenciar o negócio. A base de produção dos itens comercializados pela organização está diretamente relacionada às questões ambientais. Outro fator relevante identificado é o comportamento sociocultural, pois os hábitos e práticas se transformam e há um direcionamento para valorizar os produtos artesanais e customizados.

No cenário da empresa, conforme a percepção do empresário, o item finanças também se mostrou importante, na medida em que o preço dos produtos é mais elevado devido à sua qualidade superior de natureza artesanal. Desse modo, os indivíduos de menor poder aquisitivo 
acabam apartados da possibilidade de consumir esses produtos. Com relação ao preço, outro fator que tem influência na sua atribuição é a questão política, pois os agentes políticos direcionam o incentivo produtivo por meio de isenção de ICMS, como por exemplo de produtos in natura (não processados pela indústria), modificando assim o custo de alguns itens.

Ainda sob o ponto de vista das macrotendências, o fator tecnologia destaca-se como potencial de influenciar o setor de produtos de madeira. Existe uma correlação entre o desenvolvimento tecnológico e o ganho de produtividade na produção, refletindo no custo das mercadorias vendidas. A tecnologia tem reflexo também por toda a cadeia logística, como nos processos de armazenamento e transporte dos produtos. O prazo de entrega e a diminuição de perdas são fatores influenciados pela tecnologia.

Segundo a visão do gestor em relação ao futuro, no que diz respeito ao fator sociocultural como macrotendência, podem haver poucas mudanças que alterem o consumo de produtos artesanais. Os concorrentes, na visão do gestor, não estão preparados ou não possuem acesso a capital para investir no desenvolvimento e adoção de tecnologia nos seus produtos. Cabe ressaltar que, neste ramo, os fornecedores são fatores diretamente ligados ao sucesso do empreendimento, pois produtos de alta qualidade garantem o consumo e a fidelização do cliente.

O gestor entende que, no futuro, o quadro de consumo estará associado muito mais à qualidade que ao preço. Isso será fruto não somente das mudanças socioculturais dos hábitos de consumo, que valorizarão os produtos artesanais e customizados, mas também das tendências estruturais do mercado que pressionam empresas e fornecedores a garantir a qualidade do produto, desde a fabricação até o transporte ao local de venda. Haverá a consciência de que o acréscimo no preço é restituído pelo benefício da qualidade do produto.

Em se tratando de fornecedores, o gestor acredita que as macrotendências não exercerão pressão tão grande a não ser pelo fator tecnologia. Assim, as empresas terão que investir em novos maquinários e processos produtivos com ganhos tecnológicos para reduzir os custos enquanto se garante o nível de qualidade aceito.

Como estratégia, o gestor também ressaltou a importância de colocar o foco nos colaboradores que comercializam os produtos por meio de visitas. Neste ponto, os clientes em potencial se sentirão valorizados e terão o conforto de não saírem de seu local, ou seja, não perdem tempo deslocando-se para comprarem no estabelecimento em questão.

Tendo em vista esse contexto, foram propostos para análise três cenários, um improvável, um provável e um otimista. O primeiro significa uma redução entre 10 a $15 \%$ nas vendas em função da entrada de um novo concorrente. O cenário provável se estabelece pela 
manutenção dos resultados obtidos com a adoção das estratégias. O melhor se caracteriza pelo aumento de 5 a $10 \%$ nas vendas em função do crescimento do mercado de atuação, dentro de três anos. Assim, dentro de um cenário improvável, a estratégia reside em diminuir a margem de lucro em alguns produtos, ao mesmo tempo em que se busca novos fornecedores e canais de venda para diminuir os custos. Para o cenário provável, a adoção das mesmas estratégias é suficiente para a manutenção das vendas e, por conseguinte, do lucro atual. Na perspectiva otimista, há a possibilidade de ampliação dos canais de venda e do mercado de atuação, pois haverá maior capital disponível para investimento.

\subsection{Análise do posicionamento}

Baseou-se no modelo das cinco forças competitivas de Porter $(1979,1996)$ para levantar junto à empresa as informações que deram fundamento à análise. Assim, caracterizou-se quais são as atividades principais da empresa, os produtos não produzidos, ou seja, adquiridos para posterior revenda e o perfil dos compradores. A cadeia produtiva também foi examinada, identificando a posição da empresa perante os demais agentes produtivos.

Após esse mapeamento, as cinco forças puderam ser caracterizadas: concorrentes, consumidores, fornecedores, produtos substitutos e potenciais entrantes ligados ao setor. As empresas que atuam comercializando na região produtos da mesma natureza foram identificadas como principais concorrentes, primeira força. Como fornecedores, segunda força, estão os produtores de madeira que abastecem a empresa com os insumos produtivos. As pessoas físicas e jurídicas de Cascavel e região foram caracterizadas como os principais consumidores, terceira força. Tem-se como produtos substitutos, quarta força, aqueles advindos de produção industrial e automatizada, ou seja, não artesanal. Como potenciais entrantes, quinta força, foram identificados os pequenos artesãos e produtores autônomos que já dominam a técnica de fabricação e desejam eliminar os elos intermediários na cadeia realizando a venda direta de seus produtos.

Entre as forças competitivas relatadas acima, as que influenciam mais diretamente os resultados da empresa são os concorrentes, pois como oferecem produtos e serviços superiores, a princípio detêm o cliente. Porém, como a qualidade dos produtos é menor, o cliente acaba procurando os produtos da empresa, que possui o preço um pouco mais elevado que os da concorrência, mas é líder em qualidade. Os grandes mercados, como são clientes que compram em grandes quantidades, podem afetar diretamente nos resultados da empresa, caso parem de comprar as mercadorias. 
Diante desse contexto das forças competitivas atuantes, a empresa adotou a estratégia de manter exclusividade com o fornecedor por meio de parcerias. Preferencialmente, a empresa executa o próprio transporte dos materiais para garantir a qualidade no processo, mas eventualmente lança mão de parceiros para a entrega quando a frota não se mostra suficiente para atender a demanda.

O produto vindo do fornecedor chega à sede e é tratado pelos colaboradores qualificados, que fazem a separação e o acondicionamento do produto em embalagens adequadas à comercialização, de forma a ficar mais atrativos para o mercado consumidor. Os colaboradores também atuam para cuidar, junto aos clientes, da reposição dos produtos que estão sendo comercializados nos mercados.

Outro foco estratégico enfatizado pela empresa está no apreço pela pontualidade na entrega dos produtos. Dado que os clientes desejam ou necessitam dos produtos no menor espaço de tempo possível, a empresa investiu em uma frota própria para atendê-los. Ademais, há motoristas previamente cadastrados para o caso de avarias com os veículos próprios, terceirizando assim a entrega e mantendo a qualidade do serviço. Ao ter controle sobre o transporte, a empresa reduz os custos logísticos que se revelam nas perdas no transporte e no tempo despendido no processo.

Portanto, há a possibilidade de a mercadoria vendida ser entregue diretamente ao cliente, reduzindo os custos relacionados ao frete. Como enfrentamento estratégico das pressões das cinco forças competitivas, a empresa busca constantemente diminuir os custos dos seus produtos. Os concorrentes, em sua maioria, não possuem essa alternativa devido ao seu pequeno porte, pelas suas condições de capital e pela falta de acesso a meios adequados de transporte das mercadorias.

\subsection{Análise swot}

A análise SWOT se caracteriza pela avaliação dos pontos fortes e fracos da empresa bem como da identificação de oportunidades e ameaças do mercado (Mintzberg, 2010), conforme representado pela Figura 01. Inicialmente, como pontos fortes, o gestor atesta a qualidade dos produtos, o atendimento e o transporte feito com veículos próprios. Assim, há a flexibilidade ao mesmo tempo em que há a qualidade na entrega dos produtos em local de distribuição acessível aos potenciais clientes. Como ponto positivo ressalta-se, também, a compra de matéria prima de melhor qualidade e a qualificação dos colaboradores. Essas características são as que mais se destacaram ao longo deste estudo. 


\section{Figura 1 - Análise SWOT}
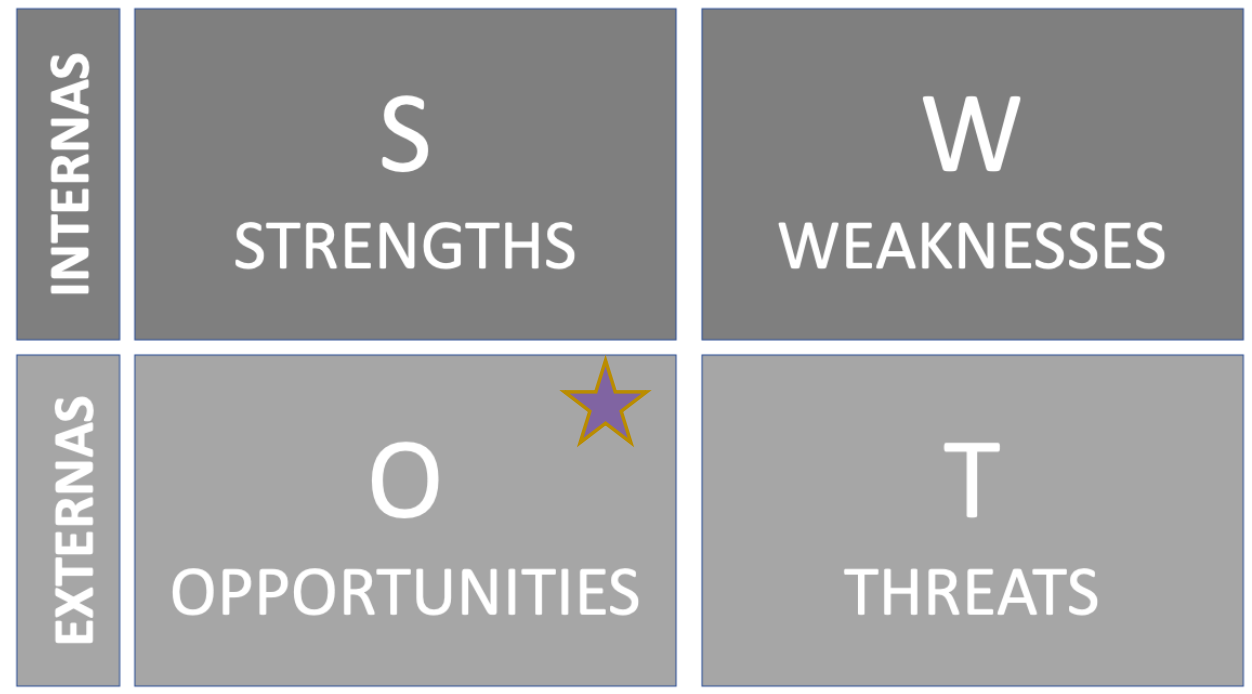

Fonte: Adaptado de Mintzberg (2010)

Olhando para as fraquezas, destacou-se o problema das sobras de produção das mercadorias vendidas, o que representa perdas financeiras. É possível diminuir esses efeitos com o reaproveitamento ou venda desses itens, ou ainda transferir parte do processo produtivo para empresas terceiras que, dada sua condição, possuem menor índice de perdas em determinado processo.

As oportunidades presentes no mercado foram focalizadas na possibilidade de venda direta dos produtos ao consumidor final. Assim, o estudo do canal de vendas online pode ser uma maneira de auferir maiores lucros aos produtos vendidos. Outro diferencial que representa uma oportunidade é a customização dos produtos vendidos por esse canal, permitindo flexibilidade na produção e diferenciação da qualidade perante os concorrentes.

Por fim, as ameaças representam condições desfavoráveis que se traduzem na sobrecarga na linha de produção quando a gestão é feita por demanda puxada (vendas). O fator político pode impactar de modo negativo quando os incentivos fiscais não são concedidos ou atendem aos segmentos comerciais concorrentes. A empresa atualmente possui relação com outras organizações como importadoras, distribuidoras, varejistas e prestadores autônomos que podem diminuir esses efeitos. Ademais, cabe ressaltar que modificações nas leis trabalhistas podem ter impacto na contratação de profissionais qualificados para a produção.

\subsection{Análise dos canais}

Além das funções desempenhadas mencionadas neste tópico, ao criar um canal de comercialização por meio de intermediários, os fabricantes podem obter diversas vantagens 
como o comércio de produtos diretamente com os consumidores (muitas empresas não dispõem de recursos financeiros para comercializar seus produtos diretamente); quando estabelecem seus próprios canais, podem obter um retorno maior investindo mais em seu negócio principal e, em alguns casos, a comercialização direta simplesmente não é viável (Kotler \& Keller, 2006).

O processo do desenvolvimento dos canais de comercialização, total ou parcial, contempla o questionamento sobre questões estratégicas a respeito de qual seria o melhor canal de comercialização, ou a melhor combinação de canais que coloque um produto no mercado da forma mais competitiva possível. Assim, para o incremento desses canais, os fabricantes precisam decidir o que é ideal, viável e o que está disponível. A segunda questão faz menção à forma de mantê-los em operação, colocando em prática os níveis de eficiência planejados. Nesse sentido, algumas etapas são essenciais para a elaboração de um projeto de canal (Novaes, 2015):

a) identificar os segmentos homogêneos de clientes: agrupar os clientes com necessidades e preferências semelhantes dentro de canais específicos;

b) identificar e priorizar funções: aquelas que são associadas a cada canal de comercialização. Tipicamente agrupadas em oito categorias (informações sobre o produto, customização do produto, afirmação da qualidade do produto, tamanho do lote, variedade, disponibilidade, serviços de pós-venda e logística);

c) benchmarking preliminar: é importante realizar a análise do projeto, confrontando-as com as melhores práticas dos concorrentes e verificando o nível de satisfação dos requisitos sob a ótica dos clientes da cadeia de suprimento;

d) fazer a revisão do projeto: combinando os resultados das análises dos passos 2 e 3 , são definidas algumas opções baseadas nos objetivos da empresa, observando-se os requisitos desejados pelos consumidores e devidamente alinhados em relação às práticas dos concorrentes;

e) avaliar custos e benefícios: avaliação dos custos e benefícios associados à geração do projeto. Importante estimar a divisão do mercado e os investimentos previstos para cada alternativa, com o objetivo de atender aos objetivos da empresa;

f) integrar com as atividades atuais da empresa: em caso de empresas já estabelecidas, é necessário integrar o projeto de comercialização à estrutura de canais existente na empresa.

Os canais de comercialização oferecem a construção de vantagens competitivas sustentáveis, por meio das características de longo prazo, tanto no planejamento quanto na 
implementação, por exigirem estrutura de organizações consistentes e terem como base pessoas e relacionamentos. Assim, pode-se entender como canal de comercialização uma rede de empresas independentes que agem em sintonia de forma a criar valor para o usuário por meio da comercialização de produtos. Neste sentido, os canais possuem como função não só satisfazerem a demanda através de produtos ou serviços no local, em quantidade, qualidade e preço adequado, mas também têm papel fundamental no estímulo à demanda, através das atividades promocionais dos componentes ou equipamentos atacadistas, varejistas, representantes e outros (Alcântara, 1997; Neves, 1999).

Ademais, ao ser definida a estratégia de comercialização de um produto ou serviço, o Administrador de Marketing precisa considerar, entre outros aspectos, os elos da cadeia de comercialização; os canais, próprios ou de intermediários, que serão utilizados; a intensidade da comercialização (intensiva, seletiva ou exclusiva); o tipo de relacionamento que será estabelecido (Pascarella, 2015).

O principal canal de venda da empresa é a venda direta através da força de vendas. A área de atuação dos vendedores é dividida conforme região geográfica, assim cada região fica a cargo de um responsável. A responsabilidade dos vendedores é atender os clientes que procuram a empresa, fazer a manutenção da carteira de clientes e prospectar novos clientes. Desse modo, o canal caracteriza-se em grande medida pela venda direta e a relação com o cliente é de fundamental importância para alcançar os objetivos e, consequentemente, o sucesso da empresa.

Tendo em vista que o principal canal de comercialização dos produtos e serviços da empresa em estudo se trata da venda pessoal (força de vendas e canal direto), a interação com o cliente é extremamente necessária para conseguir manter e aumentar os objetivos da empresa. Por se tratar do principal canal de vendas (direto), definido pelos traços, produtos e serviços trabalhados pela empresa estudada, é possível que tanto pelas vendas por indicadores de negócios diretas quanto pelas advindas de anúncios, deverão ser gerenciados os relacionamentos e vendas com os parceiros e clientes (Customer Relationship ManagementCRM ou Gerenciamento da Carteira de Clientes), que precisam ser cobrados ao término de cada atendimento, tendo em sua sequência o acompanhamento de cada operação de negócio, juntamente ao fechamento das vendas. Na venda direta, na qual a empresa possui o controle da operação, deverá ser solicitado a cada vendedor o acompanhamento dos clientes já atendidos/pós-vendas.

Para prospecção de novos clientes, sugere-se que a empresa busque canais ativos no marketing digital, tanto nas regiões onde está atuando quanto nas demais regiões. Atualmente, 
a empresa possui um canal de digital site, onde se recomenda a migração desse modelo ao modelo e-commerce, transformando a plataforma em captador de negócios, fomentando as vantagens do relacionamento entre a empresa e seus parceiros.

O sucesso alcançado pela empresa junto aos seus clientes e o mercado atendido é devido a sua força de vendas e seu desempenho em relação aos parceiros de negócio já pertencentes à carteira da empresa, além dos novos negócios originados das prospecções da equipe de vendas.

Após definir a estratégia e a estrutura da força de vendas, a empresa está pronta para pensar no tamanho que essa força deve ter. Os vendedores são um dos patrimônios mais produtivos e caros da empresa. Aumentar seu número ocasionará crescimento não só nas vendas, mas também nos custos. Uma vez estabelecida a quantidade de clientes desejada, a empresa pode usar uma abordagem de carga de trabalho para determinar o tamanho da força de vendas. Este método consiste nas seguintes etapas (Kotler \& Keller, 2006):

a) agrupar clientes de acordo com o tamanho ou volume de vendas;

b) estabelecer um anual de visitas desejável para cada classe;

c) multiplicar o número de contas em cada grupo classificado por tamanho pela frequência de visitas correspondente;

d) determinar o número médio de visitas por ano que um vendedor pode fazer;

e) determinar o número de vendedores necessários mediante a divisão do número total de visitas anuais necessárias pela média anual de visitas feita por um vendedor.

O quadro do departamento comercial, conta com 01 Vendedor. O setor está defasado, necessitando da ampliação do número de vendedores devido a área de cobertura da empresa, além da contratação de vendedores para expansão das vendas dos produtos artesanais em madeira. Neste caso, o formato ideal do tamanho da equipe de vendas seria, ao todo, 02 vendedores para as áreas atendidas em Cascavel e região e mais 01 responsável pelas vendas online.

As decisões logísticas, mais especificamente aquelas referentes à escolha e a administração dos canais de comercialização, interferem em todas as outras decisões de marketing, além de interferirem nas decisões referentes à estratégia competitiva da organização. Assim, são três as áreas que requerem decisões gerenciais quanto àescolha ou alteração do canal de comercialização: escolha de intermediários para o desempenho de funções dentro do canal, extensão do canal e intensidade da comercialização. É importante ressaltar que a escolha dos intermediários deve ser realizada de maneira criteriosa, pois estes desempenham funções que criam tempo, lugar e posse no fluxo da mercadoria (Almeida, 1999). 
A organização por cliente pode ser dividida em várias equipes de forças de venda focadas em atender setores diferentes. Exemplo: uma equipe atende aos clientes da base; outra, a abertura de novos clientes ou contas de grande importância à empresa; outro time atende aos demais, segundo a visão de Kotler e Armstrong (2003).

Esse arranjo facilita o relacionamento direto com o cliente, entretanto, assim como a forma de organização por produto, há a desvantagem da necessidade criação de várias equipes de vendedores, aumentando a cadeia hierárquica.

Segundo Kotler (1998), em situações em que há grande variedade de produtos e muitos clientes espalhados por diversas áreas geográficas, na maioria das vezes, as empresas combinam diversos modelos das organizações da força de vendas. A equipe de vendedores pode ser especializada por produto-território, cliente-território, cliente-produto e assim por diante. Logo, um membro da equipe comercial pode se reportar a mais de um gerente de área ou produto, caso seja necessário ou escolhido tal modelo para a empresa.

A adoção desse framework, conforme Moreira (2000), leva as empresas que optam por atuar dessa forma, seja pelas características e até mesmo pelo porte, a utilizarem a organização combinada, na qual é possível aproveitar as vantagens que esse framework oferece.

Levando em consideração as bibliografias antes citadas, o modelo adotado pela empresa é o da Organização Combinada da Força de Vendas. Esse modelo foi escolhido levando em consideração as linhas de produtos ofertados pela empresa, onde é possível trabalhar com linhas diferentes, mesmo em apenas uma região geográfica, levando em consideração os perfis diferentes de cada produto, clientes e vendedores a serem alocados para o alcance dos melhores resultados.

\section{5 conclusões}

Este trabalho objetivou analisar a abertura de um novo canal de venda diante do planejamento estratégico e do contexto competitivo da empresa em estudo. Fez-se a análise dos cenários possíveis elencando os principais fatores de macrotendências, bem como foi executada a análise do posicionamento estratégico da empresa em face às pressões das cinco forças competitivas, além do diagnóstico e análise SWOT que pudessem ter impacto nas atividades da organização em estudo.

Como resultado, entende-se que a empresa está ciente dos seus pontos fortes e fracos, bem como das oportunidades presentes no mercado e que poderão ser aproveitadas e das ameaças que deverão ser tratadas com cautela. Ainda que não esteja formalizado e registrado 
em um único documento escrito, o processo de planejamento estratégico foi conduzido e está acessível ao gestor para a definição dos cursos de ação da empresa.

Buscando atender ao objetivo deste trabalho em analisar a abertura de um novo canal de venda diante do planejamento estratégico e do contexto competitivo da empresa em estudo, foi adotado o modelo da Organização Combinada da Força de Vendas. Combinando, assim, o modelo de prospecção ativa da empresa com a equipe de vendedores externos e a vendas diretas pelo novo canal de comercialização, o e-commerce, podendo, enfim, utilizar estratégias de marketing digital, como apresentado na seção anterior.

Sob o ponto de vista prático, a maior contribuição deste trabalho foi o auxílio prestado ao gestor na compreensão das análises e dos benefícios que as ferramentas estratégicas possibilitam quando adotadas. Assim sendo, houve impacto positivo na operação da empresa devido à adoção do modelo de gestão estratégica, com potenciais benefícios perante seus concorrentes a partir do uso de um novo canal de vendas. Há, ainda, a possibilidade de replicação deste estudo para outras empresas com o objetivo da adoção das ferramentas que apoiam a estratégia de seus negócios. Gestores podem utilizar o presente relato técnico para entender como podem utilizar as ferramentas estratégicas citadas para o ganho em vantagem competitiva.

Como limitação, aponta-se para a restrição que advém da ressalva à ampla generalização dos resultados. O uso das ferramentas do planejamento estratégico se limita àquelas escolhidas para o desenvolvimento deste estudo. Como sugestão para trabalhos futuros, recomenda-se estender o exame para um número maior de empresas atuando neste mesmo segmento ou estudar um grupo heterogêneo de organizações que operam em segmentos diferentes, utilizando as mesmas ferramentas estratégicas.

\section{Referências}

Alcântara, R. L. C. (1997). A gestão estratégica dos canais de distribuição: um exame da evolução e do atual estágio do relacionamento entre o atacado de entrega e a indústria. São Paulo: EAESP I FGV, 1997. 194p. (Tese de Doutorado apresentada ao Curso de PósGraduação da EAESP/FGV, Área de Concentração: Mercadologia).

de Almeida, A. M. P. (1999). Sistemas de canais de distribuição: um estudo de caso na indústria alimentícia mineira. Caderno de Pesquisas em Administração, São Paulo, v.1, n8, p.51-60.

Andreuzza, M. G. S. B. (2008). Apostila de planejamento estratégico. Instituto SAGRES de Políticas e Gestão de Estratégias Aplicadas. 
Drucker, P. F. (1977). Introdução à Administração. São Paulo: Pioneira, 1977.

Hitt, M. A., Ireland, R. D., \& Hoskisson, R. E. (2011). Administração estratégica: competitividade e globalização. 2 ed. São Paulo: Cengage Learning.

Kotler, P. (1998). Administração de marketing: Análise. Planejamento, Implementação e controle, 5.

Kotler, P., \& ARMSTRONG, G. (2003). Administração de marketing. A Bíblia do Marketing, 12.

Kotler, P., \& Keller, K. L. (2006). Administração de marketing: a bíblia do marketing. 12a edição.

Mintzberg, H. (2010). Safári de estratégia: um roteiro pela selva do planejamento estratégico. 2 ed. Porto Alegre: Bookman.

Moreira, J. C. T (2000). Administração de Vendas. São Paulo: Editora Saraiva.

Neves, M. F. (1999). Um modelo para planejamento de canais de distribuição no setor de alimentos (Doctoral dissertation, Universidade de São Paulo).

Novaes, A. G. (2015). Logística e gerenciamento da cadeia de distribuição. Rio de Janeiro: Elsevier.

Oliveira, D. P. R. (2004). Planejamento estratégico: conceitos, metodologia e práticas. 20 ed. São Paulo: Atlas.

de Oliveira, L. M., Perez Junior, J. H., \& dos Santos Silva, C. A. (2011). Controladoria estratégica. Atlas.

Porter, M. E. (1979). How Competitive Forces Shape Strategy. Harvard Business Review, 57(2), 137-145.

Porter, M. E. (1996). What is strategy?. Harvard Business Review, 74(6), 61-78.

Pascarella, R. (2015). Gestão de canais de distribuição. Editora FGV.

Tripp, D. (2005). Pesquisa-ação: uma introdução metodológica. In: Educação e Pesquisa, São Paulo, 31(3), 443-466, 